\title{
MYOTIS CILIOLABRUM FOUND EAST OF ITS KNOWN RANGE
}

\section{SHELBY J. BOHN ${ }^{1}$, NICOLE LERMINIAUX, ALYSSA STULBERG}

'Department of Biology, University of Regina, Regina, SK S4S 0A2 email: shelbyjbohn@gmail.com

The range of the western small-footed bat (Myotis ciliolabrum) traditionally includes the SW corner of Saskatchewan, $S$ of the South Saskatchewan River and W of Regina. ${ }^{1}$ On May 27, 2014 a dead specimen of $M$. ciliolabrum was found at the Indian Head Golf Club in Indian Head, Saskatchewan (50³2'22" N, 103 $39^{\circ} 42^{\prime \prime}$ W), well east of its usual range. The specimen had light fur and the dark eye mask characteristic of this species. This location was unusual because this species generally prefers arid or semi arid environments where individuals roost in rock crevices $^{2}$, while Indian Head, SK and the surrounding area is wetter, and lacks rocky outcrops. This suggests that the bat was transient, especially since the last few years have been even wetter than average. The bat was found underneath a drainpipe leading to the ground following a heavy downpour. It is possible that the bat may have been roosting within the pipe when the rain started.

1. van Zyll de Jong, C.G. 1985. Handbook of Canadian Mammals 2 Bats. National Museums of Canada. Ottawa, ON.

2. Holloway, G.L. and Barclay, M.R. 2001. Myotis ciliolabrum. Mammalian Species. 670:1-5. 


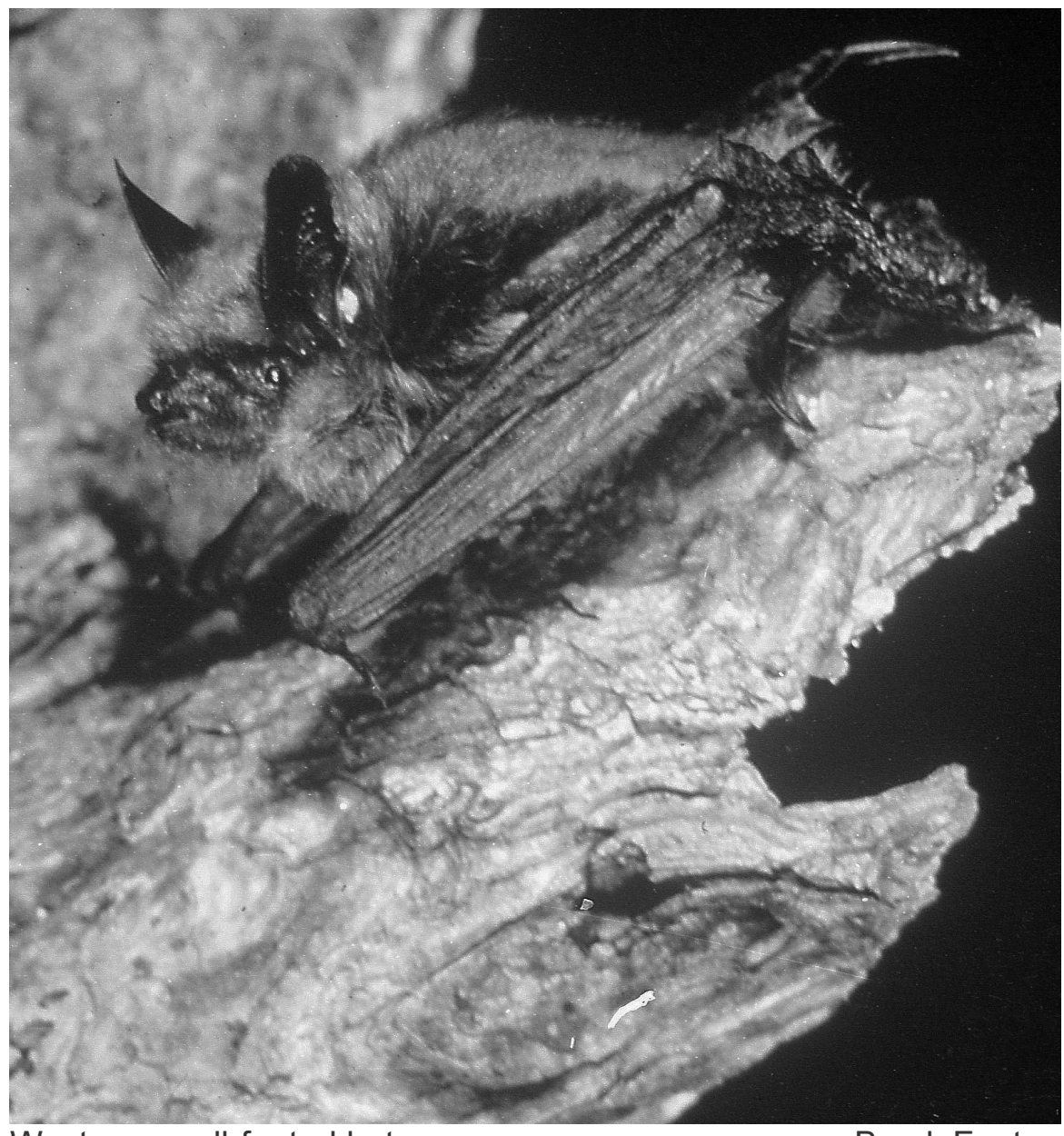

Western small-footed bat

- Brock Fenton

72 (4) December 2014 